\title{
Hysteresis in Clay Swelling Induced by Hydrogen Bonding: Accurate Prediction of Swelling States
}

\author{
Tim J. Tambach, ${ }^{*, \dagger}$ Peter G. Bolhuis, ${ }^{\dagger}$ Emiel J. M. Hensen, ${ }^{\ddagger}$ and Berend Smit ${ }^{\dagger, \S}$ \\ Van 't Hoff Institute for Molecular Sciences, Universiteit van Amsterdam, Nieuwe Achtergracht 166, 1018 \\ WV Amsterdam, The Netherlands, Schuit Institute of Catalysis, Eindhoven University of Technology, Post \\ Office Box 513, 5600 MB Eindhoven, The Netherlands, and CECAM (Centre Européen de Calcul \\ Atomique Moléculaire), Ecole Normale Supérieure, 46 Allée d'Italie, 69364 Lyon Cedex 7, France
}

Received May 23, 2005. In Final Form: October 14, 2005

\begin{abstract}
We perform grand-canonical molecular simulations to study the molecular mechanism of clay swelling hysteresis as a function of the relative humidity. In particular, we focus on the transition from the one- to the two-layer hydrate and the influence of three types of counterions $\left(\mathrm{Li}^{+}, \mathrm{Na}^{+}\right.$, and $\left.\mathrm{K}^{+}\right)$. Our results cover the experimental relative humidity region where swelling and shrinking usually occur. We show that the thermodynamic origin of swelling hysteresis is a free-energy barrier separating the layered hydrates. This free-energy barrier is dominated by breaking and formation of hydrogen bonds between and within water layers. This network of water molecules is similar for all counterions, but the positions of these counterions depend upon their size. The relatively large $\mathrm{K}^{+}$counterions show more affinity for clay surface adsorption, which increases the free-energy barrier and inhibits swelling. On the other hand, the relatively small $\mathrm{Li}^{+}$counterions are quite well-accommodated in the water network, and thereby, they can form a new swelling state with a basal spacing of approximately $13.5 \AA$. This new swelling state is an alternative explanation for the widely accepted simultaneous occurrence of two or more swelling phases.
\end{abstract}

\section{Introduction}

Clay minerals are an important class of materials. Together with water, they are the most common substances in the Earths crust, ${ }^{1}$ and they dominate the mineralogy of soils and sediments. ${ }^{2}$ A striking feature of some clay minerals is that the adsorption of water can cause extreme swelling, thereby increasing the volume with an order of magnitude. Clay minerals are also used in many different applications, such as construction materials, drilling muds, cosmetics, radioactive waste disposals, or catalysis. ${ }^{3,4}$ For these applications, it is important to control the swelling behavior. Experiments show that swelling proceeds stepwise, related to the formation of water layers between the clay platelets. ${ }^{5,6}$ Interestingly, this swelling shows hysteresis; the adsorption and desorption proceed differently. $5,7-20$

* To whom correspondence should be addressed. Telephone: +31-302564793. Fax: +31-30-2564475. E-mail: tim.tambach@tno.nl.

$\checkmark$ Van 't Hoff Institute for Molecular Sciences, University of Amsterdam.

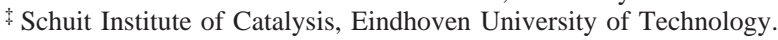

$\&$ CECAM.

(1) Low, P. F. Adv. Agron. 1961, 13, 269-327.

(2) Bleam, W. F. Rev. Geophys. 1993, 31, 51-73

(3) Grim, R. E. Applied Clay Mineralogy; McGraw-Hill: New York, 1962.

(4) Hanczyc, M. M.; Fujikawa, S. M.; Szostak, J. W. Science 2003, 302, $618-622$.

(5) Norrish, K. Discuss. Faraday Soc. 1954, 18, 120-134.

(6) MacEwan, D. M. C.; Wilson, M. J., in Crystal Structures of Clay Minerals and Their X-ray Identification; Brindley, G. W.; Brown, G., Eds.; Mineralogical Society: London, U.K., 1980, Vol. 5, Chapter 3, pp 197-248.

(7) Mooney, R. W.; Keenan, A. G.; Wood, L. A. J. Am. Chem. Soc. 1952, 74, $1367-1371$.

(8) van Olphen, H. J. Colloid Sci. 1965, 20, 822-837.

(9) Laffer, B. G.; Posner, A. M.; Quirk, J. P. Clay Miner. 1966, 6, 311-321.

(10) Kittrick, J. A. Soil Sci. Soc. Am. J. 1969, 33, 217-222.

(11) Keren, R.; Shainberg, I. Clays Clay Miner. 1975, 23, 193-200 492.

(12) Fu, M. H.; Zhang, Z. Z.; Low, P. F. Clays Clay Miner. 1990, 38, 485-

(13) Wada, N.; Hines, D. R.; Ahrenkiel, S. P. Phys. Rev. B 1990, 41, 1289512902.

(14) Cases, J. M.; Bérend, I.; Besson, G.; François, M.; Uriot, J.-P.; Thomas, F.; Poirier, J. E. Langmuir 1992, 8, 2730-2739.

(15) Bérend, I.; Cases, J. M.; Francois, M.; Uriot, J.-P.; Michot, L.; Masion, A.; Thomas, F. Clays Clay Miner. 1995, 43, 324-336.

(16) Cases, J. M.; Bérend, I.; François, M.; Uriot, J. P.; Michot, L. J.; Thomas, F. Clays Clay Miner. 1997, 45, 8-22.
The swelling of 2:1 layer silicates (e.g., montmorillonite or vermiculite) is induced by hydration of charge-compensating counterions in the interlayer space of clay minerals. A typical way of quantifying the swelling is to measure the water content and the basal spacing of the clay mineral as a function of the relative humidity, ${ }^{7-9,11,12,14-17,19,21-28}$ salt concentration, ${ }^{5,9,29,30}$ temperature, ${ }^{10,13,18-20}$ or external pressure. ${ }^{18,31,32}$ In addition, several types of clay minerals with varying layer charge $^{23,26,27,29,30,33}$ or type of cation ${ }^{5,9-11,15-19,21-24,26-28,30}$ show different hydration and swelling properties. Although the hysteresis in clay swelling has been extensively studied d $^{5-20}$ Laird et al. ${ }^{34}$ point out the little consensus on the molecular origin of clay swelling hysteresis. Explanations are given in terms of structural rearrangements in the clay $8,12,35,36$ or changes in interactions between layers upon expansion or contraction. ${ }^{10,37}$

(17) Chipera, S. J.; Carey, J. W.; Bish, D. L. in Advances in X-ray Analysis Gilfrich, J. V.; Jenkins, R.; Snyder, R. L., Eds.; Plenum Press: New York, 1997; Vol. 39, pp 713-722.

(18) Wu, T.-Z.; Bassett, W. A.; Guggenheim, W.-L. S.; Koster van Groos, A F. Am. Miner. 1997, 82, 69-78.

(19) Xu, W.; Johnston, C. T.; Parker, P.; Agnew, S. F. Clays Clay Miner. 2000, $48,120-131$.

(20) da Silva, G. J.; Fossum J. O.; DiMasi, E.; Maloy, K. J. Phys. Rev. B 2003, 67, 094114-094116.

(21) Hendricks, S. B.; Nelson, R. A.; Alexander, L. T. J. Am. Chem. Soc. 1940 , $62,1457-1464$.

(22) Mooney, R. W.; Keenan, A. G.; Wood, L. A. J. Am. Chem. Soc. 1952, $74,1371-1374$.

(23) Gillery, F. H. Am. Miner. 1959, 44, 806-818.

(24) Messina, M. L. Proc. Natl. Conf. Clays Clay Miner., 12th 1964, 12 , 617-632.

(25) van Olphen, H. Proc. Natl. Conf. Clays Clay Miner., 11th 1963, 178187.

(26) Sato, T.; Watanabe, T.; Otsuka, R. Clays Clay Miner. 1992, 40, 103-113.

(27) Chiou, C. T.; Rutherford, D. W. Clays Clay Miner. 1997, 45, 867-880.

(28) Tamura, K.; Yamada, H.; Nakazawa, H. Clays Clay Miner. 2000, 48, 400-404.

(29) Slade, P. G.; Quirk, J. P.; Norrish, K. Clays Clay Miner. 1991, 39, 234238.

(30) Slade, P. G.; Quirk, J. P. J. Colloid Interface Sci. 1991, 144, 18-26.

(31) Koster van Groos, A. F.; Guggenheim, S. Am. Miner. 1984, 69, 872-879.

(32) Colten, V. A. Clays Clay Miner. 1986, 34, 385-389.

(33) Laird, D. A. Clays Clay Miner. 1999, 47, 630-636.

(34) Laird, D. A.; Shang, C.;.Thompson, M. L. J. Colloid Interface Sci. 1995 $171,240-245$ 
Others suggested that layered hydrates are phases and the swelling and shrinking of clay minerals are phase transitions causing hysteresis. ${ }^{13,20,28,38}$ Heterogeneity of surface properties make the system more complex, because conditions that induce a phase transition in one domain may not cause a phase transition in other domains of the same sample. ${ }^{38}$

Molecular simulations have proven to be a powerful tool to obtain more insight in the swelling behavior of clay minerals on a molecular scale. ${ }^{36,39-61}$ Computations confirmed that the swelling occurs stepwise and that water molecules form layers in the interlayer space. ${ }^{36,42,56}$ The simulated equilibrium basal spacings as a function of the water content are in good agreement with experimental measurements. ${ }^{36,42,49}$ In addition, it is shown that the distribution of counterions in the interlayer space depends upon the basal spacing, ${ }^{42,45,46,48,56,59}$ the type of counterion, ${ }^{42,45,46,48,55,58,59}$ and the type of isomorphic substitutions in the clay mineral structure..$^{4,59}$ The formation of complexes between the clay platelets and the counterions significantly influences the mobility of these cations in the interlayer space. ${ }^{45,46,48,52}$ To mimic geological conditions, elevated pressure and temperature are also taken into account. $47,57,58,60,61$

Up to now, a relatively small number of simulation studies have been carried out to understand clay swelling hysteresis. ${ }^{36,42,51,56,60}$ These simulation studies pointed at different mechanisms responsible for hysteresis. In their simulations, Boek et al. ${ }^{36}$ do not observe a hysteresis loop and conclude that the basal spacing (and other thermodynamic quantities) are independent of the initial configuration of the system. From the absence of hysteresis, Boek et al. ${ }^{36}$ conclude that the irreversibility of the swelling curves most likely arises from minor strain within the clay layer structure. However, Hensen and $\mathrm{Smit}^{56}$ do observe a hysteresis loop of the basal spacing in their simulations, sug-

(35) Everett, D. H. in The Solid-Gas Interface; Flood, E. A., Ed.; Marcel Dekker: New York, 1967, pp 1055-1113.

(36) Boek, E. S.; Coveney, P. V.; Skipper, N. T. Langmuir 1995, 11, 46294631

(37) Hirst, W. Discuss. Faraday Soc. 1947, 3, 22-28.

(38) Laird, D. A.; Shang, C. Clays Clay Miner. 1997, 45, 681-689.

(39) Delville, A.; Sokolowski, S. J. Phys. Chem. 1993, 97, 6261-6271.

(40) Delville, A. J. Phys. Chem. 1993, 97, 9703-9712.

(41) Karaborni, S.; Smit, B.; Heidug, W.; Urai, J.; van Oort, E. Science 1995, 271, 1102-1104.

(42) Boek, E. S.; Coveney, P. V.; Skipper, N. T. J. Am. Chem. Soc. 1995, 117, $12608-12617$

(43) Skipper, N. T.; Chang, F.-R. C.; Sposito, G. Clays Clay Miner. 1995, 43 , $285-293$.

(44) Skipper, N. T.; Sposito, G.; Chang, F.-R. C. Clays Clay Miner. 1995, 43, 294-303.

(45) Chang, F.-R. C.; Skipper, N. T.; Sposito, G. Langmuir 1995, 11, $2734-$ 2741

(46) Chang, F.-R. C.; Skipper, N. T.; Sposito, G. Langmuir 1997, 13, 20742082

(47) de Siqueira, A. V. C.; Skipper, N. T.; Coveney, P. V.; Boek, E. S. Mol. Phys. 1997, 92, 1-6.

(48) Chang, F.-R. C.; Skipper, N. T.; Sposito, G. Langmuir 1998, 14, $1201-$ 1207

(49) Smith, D. E. Langmuir 1998, 14, 5959-5967.

(50) Shroll, R. M.; Smith, D. E. J. Chem. Phys. 1999, 111, 9025-9033.

(51) Young, D. A.; Smith, D. E. J. Phys. Chem. B 2000, 104, 9163-9170.

(52) Sutton, R.; Sposito, G. J. Colloid Interface Sci. 2001, 237, 174-184.

(53) Chávez-Páez, M.; van Workum, K.; de Pablo, L.; de Pablo, J. J. J. Chem. Phys. 2001, 114, 1405-1413.

(54) Chávez, M.; de Pablo, L.; de Pablo, J. J. J. Chem. Phys. 2001, 114, $10948-10953$

(55) Hensen, E. J. M.; Tambach, T. J.; Bliek, A.; Smit, B. J. Chem. Phys. 2001, $115,3322-3329$

(56) Hensen, E. J. M.; Smit, B. J. Phys. Chem. B 2002, 106, 12664-12667.

(57) de Pablo, L.; Chávez, M. L.; Sum, A. K.; de Pablo, J. J. J. Chem. Phys.

2004, 120, 939-946.

(58) Whitley, H. D.; Smith, D. E. J. Chem. Phys. 2004, 120, 5387-5395.

(59) Tambach, T. J.; Hensen, E. J. M.; Smit, B. J. Phys. Chem. B 2004, 108 , $7586-7596$.

(60) Tambach, T. J.; Bolhuis, P. G.; Smit, B. Angew. Chem. Int. Ed. 2004, 43, $2650-2652$. 2016

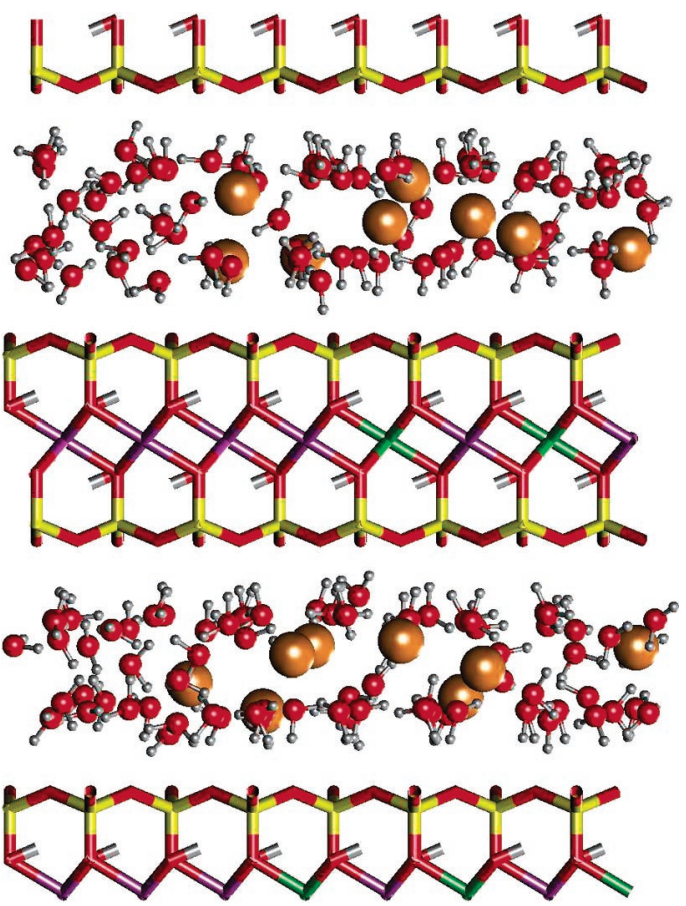

Figure 1. Snapshot of a two-layer hydrate of Arizona Kmontmorillonite with a basal spacing of $14.75 \AA$ at a relative humidity of $67 \%$. The tubes represent the clay structure, and the spheres represent the water molecules and cations. In the clay, $\mathrm{O}=$ red, $\mathrm{H}$ $=$ silver, $\mathrm{Si}=$ yellow, $\mathrm{Al}=$ purple, and $\mathrm{Mg}=$ green. For water, $\mathrm{O}=$ red, $\mathrm{H}=$ silver, and cation $\mathrm{K}=$ orange.

gesting a thermodynamic origin of hysteresis. These differences motivate us to investigate the swelling mechanism in more detail. A preliminary report of these simulations is published in ref 60 .

From a computational point of view, one can study the swelling of clay minerals using different types of ensembles. Indeed, simulation studies are reported using $N P T, 36,42-49,52-54,62$ $\mu V T,{ }^{39-41,50,53-60,6363}$ and $\mu P T^{56}$ simulation techniques. Experimentally, the clay mineral is in open contact with a water reservoir. Therefore, grand-canonical simulations with a fixed water chemical potential $(\mu)$, equivalent to the relative humidity, mimic the experimental setup more closely than simulations with a fixed number of water molecules $(N)$. In some grand-canonical studies, it is suggested that clay swelling is a phase transition..$^{50,58}$ In our previous work, ${ }^{59}$ we report molecular simulations of the swelling of clay minerals by varying the water chemical potential and basal spacing. In this work, we use similar methods to study the influence of the type of cation $\left(\mathrm{Li}^{+}, \mathrm{Na}^{+}\right.$, and $\left.\mathrm{K}^{+}\right)$on the swelling hysteresis of Arizona montmorillonite.

\section{Methodology}

In this section, we give a short description of the models and computational aspects. More details can be found in refs 42, 43, 53, 55,56 , and 59 .

2.1. Clay Mineral Structure. We focus on montmorillonite clay minerals, which are part of the smectite group and known for their swelling properties. ${ }^{6}$ The atom types and corresponding charges of one unit cell of the dioctahedral clay crystal ${ }^{43}$ are reproduced in Table 1 . We carry out random substitutions, obeying Lowenstein's rule, ${ }^{64}$ of $\mathrm{Al}^{3+}$ by $\mathrm{Mg}^{2+}$ in the octahedral sheet modeling Arizona montmorillonite. We define the unit-cell formula of this clay mineral as $\mathrm{M}_{1.0}\left[\mathrm{Si}_{8.0}\right]\left[\mathrm{Al}_{3.0} \mathrm{Mg}_{1.0}\right] \mathrm{O}_{20}(\mathrm{OH})_{4}$, and $\mathrm{M}$ represents a monovalent

(62) Skipper, N. T.; Refson, K.; McConnell, J. D. C. J. Chem. Phys. 1991, 94 $7434-7445$.

(63) de Lourdes Chávez, M.; de Pablo, L.; de Pablo, J. J. Langmuir 2004, 20 , 10764-10770.

(64) Lowenstein, W. Am. Miner. 1954, 39, 92-96. 
Table 1. Coordinates and Partial Charges of Atoms in the Clay Crystal Structure of One Unit Cell of Montmorillonite ${ }^{43}$

\begin{tabular}{ccccccccrrrr}
\hline number & atom type & $x(\AA)$ & $y(\AA)$ & $z(\AA)$ & $q_{\mathrm{i}}(\mathrm{e})$ & number & atom type & $x(\AA)$ & $y(\AA)$ & $z(\AA)$ & $q_{\mathrm{i}}(\mathrm{e})$ \\
\hline 1 & $\mathrm{O}$ & 2.64 & 0.00 & 3.28 & -0.8000 & 21 & $\mathrm{Al}$ & 7.06 & 6.09 & 0.00 & 3.0000 \\
2 & $\mathrm{O}$ & 1.32 & 2.28 & 3.28 & -0.8000 & 22 & $\mathrm{Al}$ & 7.06 & 3.05 & 0.00 & 3.0000 \\
3 & $\mathrm{O}$ & 3.96 & 2.28 & 3.28 & -0.8000 & 23 & $\mathrm{O}$ & 0.88 & 9.14 & -3.28 & -0.8000 \\
4 & $\mathrm{O}$ & 0.00 & 0.00 & 1.06 & -1.7175 & 24 & $\mathrm{O}$ & 2.20 & 6.86 & -3.28 & -0.8000 \\
5 & $\mathrm{H}$ & 0.8815 & 0.00 & 1.434 & 0.7175 & 25 & $\mathrm{O}$ & -0.44 & 6.86 & -3.28 & -0.8000 \\
6 & $\mathrm{Si}$ & 2.64 & 1.52 & 2.73 & 1.2000 & 26 & $\mathrm{O}$ & 3.52 & 9.14 & -1.06 & -1.7175 \\
7 & $\mathrm{Si}$ & 0.00 & 3.05 & 2.73 & 1.2000 & 27 & $\mathrm{H}$ & 2.6385 & 9.14 & -1.434 & 0.7175 \\
8 & $\mathrm{O}$ & 2.64 & 1.52 & 1.06 & -1.0000 & 28 & $\mathrm{Si}$ & 0.88 & 7.62 & -2.73 & 1.2000 \\
9 & $\mathrm{O}$ & 0.00 & 3.05 & 1.06 & -1.0000 & 29 & $\mathrm{Si}$ & 3.52 & 6.09 & -2.73 & 1.2000 \\
10 & $\mathrm{Al}$ & 4.40 & 1.52 & 0.00 & 3.0000 & 30 & $\mathrm{O}$ & 0.88 & 7.62 & -1.06 & -1.0000 \\
11 & $\mathrm{Al}$ & 4.40 & -1.52 & 0.00 & 3.0000 & 31 & $\mathrm{O}$ & 3.52 & 6.09 & -1.06 & -1.0000 \\
12 & $\mathrm{O}$ & 0.00 & 4.57 & 3.28 & -0.8000 & 32 & $\mathrm{O}$ & 3.52 & 4.57 & -3.28 & -0.8000 \\
13 & $\mathrm{O}$ & 3.96 & 6.85 & 3.28 & -0.8000 & 33 & $\mathrm{O}$ & -0.44 & 2.29 & -3.28 & -0.8000 \\
14 & $\mathrm{O}$ & 1.32 & 6.85 & 3.28 & -0.8000 & 34 & $\mathrm{O}$ & 2.20 & 2.29 & -3.28 & -0.8000 \\
15 & $\mathrm{O}$ & 2.64 & 4.57 & 1.06 & -1.7175 & 35 & $\mathrm{O}$ & 0.88 & 4.57 & -1.06 & -1.7175 \\
16 & $\mathrm{H}$ & 3.5215 & 4.57 & 1.434 & 0.7175 & 36 & $\mathrm{H}$ & -0.0015 & 4.57 & -1.434 & 0.7175 \\
17 & $\mathrm{Si}$ & 0.00 & 6.09 & 2.73 & 1.2000 & 37 & $\mathrm{Si}$ & 3.52 & 3.05 & -2.73 & 1.2000 \\
18 & $\mathrm{Si}$ & 2.64 & 7.62 & 2.73 & 1.2000 & 38 & $\mathrm{Si}$ & 0.88 & 1.52 & -2.73 & 1.2000 \\
19 & $\mathrm{O}$ & 0.00 & 6.09 & 1.06 & -1.0000 & 39 & $\mathrm{O}$ & 3.52 & 3.05 & -1.06 & -1.0000 \\
20 & $\mathrm{O}$ & 2.64 & 7.62 & 1.06 & -1.0000 & 40 & $\mathrm{O}$ & 0.88 & 1.52 & -1.06 & -1.0000
\end{tabular}

counterion. To ensure that our simulation cell is sufficiently large, we use two clay platelets of eight unit cells each and $x$ and $y$ dimensions of 21.12 and $18.28 \AA$, respectively. The $z$ dimension of the system is defined by 2 times the basal spacing, which is the sum of the clay platelet thickness and the interlayer space. The eight unit cells of a clay layer have a total layer charge of $8 \mathrm{e}$, which is compensated by an equivalent amount of counterions in each interlayer. We investigate the influence of three types of counterions: $\mathrm{Li}^{+}, \mathrm{Na}^{+}$, and $\mathrm{K}^{+}$. Figure 1 shows a typical snapshot of Arizona K-montmorillonite with a basal spacing of $14.75 \AA$ containing two layers of water molecules in each interlayer.

2.2. Potential Parameters. In our simulations, the total potential energy is defined ${ }^{42}$ as a combination of the van der Waals energy $\left(U_{\text {VDW }}\right)$ and Coulombic energy $\left(U_{\text {Coul }}\right)$

$$
U_{\text {pot }}=U_{\mathrm{VDW}}+U_{\mathrm{Coul}}
$$

with

$$
U_{\mathrm{VDW}}=\sum_{i=1}^{N} \sum_{j>i}^{N} \frac{A_{i j}}{r_{i j}^{12}}-\frac{B_{i j}}{r_{i j}^{6}}+C_{i j} \exp \left[-D_{i j} r_{i j}\right]-\frac{E_{i j}}{r_{i j}^{4}}
$$

and

$$
U_{\mathrm{Coul}}=\sum_{i=1}^{N} \sum_{j>i}^{N} \frac{q_{i} q_{j}}{r_{i j}}
$$

In eq 2, $A, B, C, D$, and $E$ are van der Waals interaction parameters, and depending upon atom types, parts of this potential are used. In our simulations, we use the TIP4P water mode ${ }^{65}$ and the parameters for counterions $\mathrm{Li}^{+}$and $\mathrm{Na}^{+}$are taken from Chandrasekhar et al. ${ }^{66}$ Because parameters for $\mathrm{K}^{+}$are not available from this source, we follow the approach of Boek et al. ${ }^{42}$ by using the parameters of Bounds. ${ }^{67}$ We should keep in mind that this approach may induce different effects for $\mathrm{K}^{+}$. Table 2 lists the complete set of parameters. The distance between the atoms is given by $r_{i j}$, and the partial charges of the atoms are defined as $q_{i}$ and $q_{j}$.

2.3. Simulation Details. During the grand-canonical simulations, the clay mineral can exchange water molecules with a water reservoir, which is accomplished through a configurational bias Monte Carlo technique ${ }^{55,68}$ at a fixed water chemical potential $\left(\mu_{\text {water }}\right)$. We impose

(65) Jorgensen, W. L.; Chandrasekhar, J.; Madura, J.; Impey, R. W.; Klein, M. J. Chem. Phys. 1983, 79, 926-935.

(66) Chandrasekhar, J.; Spellmeyer, D. C.; Jorgensen, W. L. J. Am. Chem. Soc. 1984, 106, 903-910.

(67) Bounds, D. G. Mol. Phys. 1985, 54, 1335-1355.

(68) Frenkel, D.; Smit, B. Understanding Molecular Simulation: From Algorithms to Applications, 2nd ed.; Academic Press: San Diego, CA, 1996.
Table 2. van der Waals Parameters (eq 2) Describing

\begin{tabular}{|c|c|c|c|c|c|}
\hline & $\begin{array}{c}A \\
\left(\mathrm{kcal}^{12}\right. \\
\left.\mathrm{mol}^{-1}\right)\end{array}$ & $\begin{array}{c}B \\
\left(\mathrm{kcal}^{\circ}{ }^{6}\right. \\
\left.\mathrm{mol}^{-1}\right)\end{array}$ & $\begin{array}{c}C \\
\left(\mathrm{kcal}^{-1}\right) \\
\left.\mathrm{mol}^{-1}\right)\end{array}$ & $\begin{array}{c}D \\
\left(\AA^{-1}\right)\end{array}$ & $\begin{array}{c}E \\
\left(\mathrm{kcal}^{4}\right. \\
\left.\mathrm{mol}^{-1}\right)\end{array}$ \\
\hline $\mathrm{O}-\mathrm{O}$ & $600.0 \times 10^{3}$ & 610.0 & 0.0 & 0.0 & 0.0 \\
\hline $\mathrm{Li}-\mathrm{Li}$ & 400.0 & 100.0 & 0.0 & 0.0 & 0.0 \\
\hline $\mathrm{Li}-\mathrm{O}$ & $15.5 \times 10^{3}$ & 247.0 & 0.0 & 0.0 & 0.0 \\
\hline $\mathrm{Na}-\mathrm{Na}$ & $14.0 \times 10^{3}$ & 300.0 & 0.0 & 0.0 & 0.0 \\
\hline $\mathrm{Na}-\mathrm{O}$ & $91.7 \times 10^{3}$ & 427.8 & 0.0 & 0.0 & 0.0 \\
\hline $\mathrm{K}-\mathrm{O}$ & 0.0 & -638.0 & $53.884 \times 10^{3}$ & 3.339 & 438.0 \\
\hline $\mathrm{K}-\mathrm{H}$ & 0.0 & 0.0 & $5.747 \times 10^{3}$ & 3.4128 & 0.0 \\
\hline $\mathrm{K}-\mathrm{Si}$ & 0.0 & 0.0 & 19.0 & 0.749 & 0.0 \\
\hline $\mathrm{K}-\mathrm{Al}$ & 0.0 & 0.0 & 19.0 & 0.749 & 0.0 \\
\hline $\mathrm{K}-\mathrm{Mg}$ & 0.0 & 0.0 & 19.0 & 0.749 & 0.0 \\
\hline
\end{tabular}
Interactions between Water, Cations, and the Clay Atoms ${ }^{42,65-67}$ for Simulations with the TIP4P Water Model ${ }^{a}$

${ }^{a}$ The oxygen atoms represent the oxygen atoms of water and the clay structure. As it becomes clear from the table, only parts of the potential are used for specific interactions.

the temperature $(T)$ and volume $(V)$ in our simulations. The Monte Carlo moves are combined with molecular dynamics with a time step of 1.0 fs. We employ the SHAKE algorithm ${ }^{69}$ to maintain the rigidity of the water molecules, and we keep the clay atoms frozen during the simulation. We perform the simulations at a temperature of $298 \mathrm{~K}$. We equilibrate the system using the Evans thermostat ${ }^{70,71}$ and use the Nosé-Hoover thermostat ${ }^{71,72}$ in the remainder of the simulation. For every fixed basal spacing and water chemical potential, we carry out particle equilibration for $50 \mathrm{ps}$ and sampling for $250 \mathrm{ps}$. The long-range Coulombic interactions are treated with the Ewald summation ${ }^{68,69}$ with $\alpha=0.35$ and $8 \leq k \leq 13$. We truncate and shift the van der Waals potentials at $9.14 \AA$ and apply periodic boundary conditions.

2.4. Simulation Setup. Our simulations mimic the experimental setup shown in Figure 2 and represent the use of a surface force apparatus (SFA). Such an apparatus can be used to measure the force between surfaces as a function of the distance between the surfaces. A detailed description of the SFA is given by Israelachvili ${ }^{73}$ and, among others, includes references to studies on mica and silica surfaces using the SFA. In the present work, the idea is that we compute the force or the pressure required for maintaining the clay system at a fixed basal spacing for a given relative humidity and

(69) Allen, M. P.; Tildesley, D. J. Computer Simulation of Liquids Clarendon Press: Oxford, U.K., 1987.

(70) Evans, D. J.; Morriss, G. P. Comput. Phys. Rep. 1984, 1, 297-343.

(71) Smith, W.; Leslie, M.; Forester, T. F. The DL-POLY 2 User Manual, version 2.14, CCLRC, Daresbury Laboratory: Daresbury, Warrington, U.K., 2003.

(72) Hoover, W. G. Phys. Rev. A 1985, 31, 1695-1697.

(73) Israelachvili, J. N. Surf. Sci. Rep. 1992, 14, 109-159. 


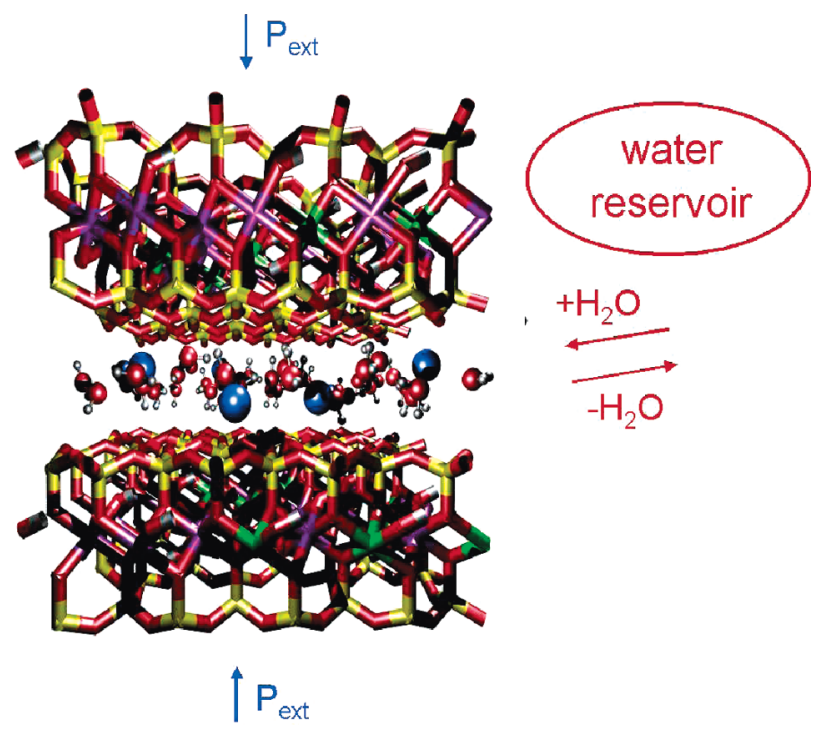

Figure 2. Setup of the simulated system, corresponding to experimental measurements with the surface force apparatus. ${ }^{73} \mathrm{We}$ fix the basal spacing in our simulations, and we measure the swelling pressure of the system. The clay mineral is in contact with a reservoir that imposes the temperature and water chemical potential (or relative humidity). After the simulations, the equilibrium basal spacing can be determined for a chosen external pressure $\left(P_{\text {ext }}\right)$, independently from the internal pressure.

temperature. As we compute these internal pressures for a large number of basal spacings at similar conditions, we retrieve information about the pressure profile as a function of the basal spacing. In a normal swelling experiment, the external pressure $\left(P_{\text {ext }}\right)$ is usually fixed at $1 \mathrm{~atm}$, and hence, the equilibrium basal spacing is measured. However, we argue that once we know the internal pressure as a function of the basal spacing, we can determine the equilibrium basal spacing for a given value of the external pressure, independently from the internal pressure.

To relate the simulation results to experimental data, we convert the imposed water chemical potential to the relative humidity using

$$
R H=100 \frac{\phi\left(P_{\text {water }}^{\text {sat }}\right)}{\phi\left(P_{\text {water }}\right)} \exp \left[-\left(\mu_{\text {water }}^{\text {sat }}-\mu_{\text {water }}\right) / R T\right]
$$

where $\phi\left(P_{\text {water }}\right)$ and $\phi\left(P_{\text {water }}^{\text {sat }}\right)$ are the fugacity coefficients at a given and at the saturated relative humidity, respectively. $\mu_{\text {water }}$ and $\mu_{\text {water }}^{\text {sat }}$ are the water chemical potentials at a given and at saturated relative humidity, $R$ is the gas constant, and $T$ is the temperature. We compute a value of $-44.5 \pm 0.2 \mathrm{~kJ} \mathrm{~mol}^{-1}$ for $\mu_{\text {water }}^{\text {sat }}$ and we use the experimental equation of the state ${ }^{74}$ to compute a value of 0.817 for $\phi\left(P_{\text {water }}^{\text {sat }}\right)$. In practice, $\phi\left(P_{\text {water }}\right)$ only becomes important at a high relative humidity. During each simulation, the average number of water molecules, the average pressure normal to the clay platelets $\left(P_{z}\right)$, and the average molecular structures (density profiles) are sampled. We convert the number of water molecules to water content by dividing the mass of the water molecules $\left(M_{\text {water }}\right)$ by the mass of the clay platelets and counterions $\left(M_{\text {clay }}\right)$. The pressure is computed using the trial volume method ${ }^{59,68}$ and includes all interactions between water molecules, cations, and clay atoms. As we carry out simulations for a range of basal spacings, we sample data for stable basal spacings but also for nonstable basal spacings. As we convert the pressure to the free energy, this technique allows us to examine what the free-energy barriers between the stable states are. As for swelling and shrinking, these free-energy barriers have to be taken. Although the stable states are discrete, it is important to emphasize that information on unstable states are required to understand the molecular mechanism of swelling and shrinking.

(74) Aspen Plus, version 11.1, Aspen Technology Inc., Polymer Technology Division: Cambridge, MA, 2001.

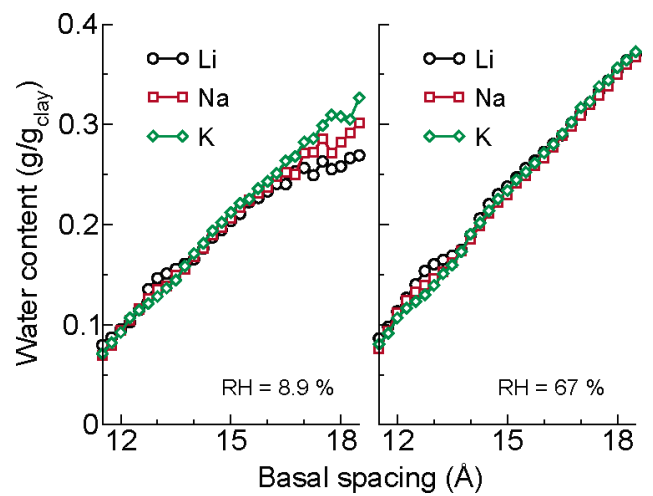

Figure 3. Simulated water content as a function of the basal spacing for Arizona $\mathrm{Li}^{-}, \mathrm{Na}-$, and $\mathrm{K}-\mathrm{montmorillonite}$ at low (left) and intermediate (right) relative humidities of 8.9 and $67 \%$, respectively. The stable states correspond to the free-energy minima in Figure 5. The other data correspond to unstable states and hence the freeenergy barriers.

We obtain the free energy $\left[\Delta F=F\left(\Delta s_{z}\right)-F\left(\Delta s_{z}^{0}\right)\right]$ per clay platelet area $(A)$ by integrating $P_{z}$ as a function of the basal spacing $\left(s_{z}\right)$, using the following formula: ${ }^{50,59}$

$$
\Delta F / A=-\int_{s_{z}^{0}}^{s_{z}}\left(P_{z}\left(s_{z}^{\prime}\right)-P_{\text {ext }}\right) \mathrm{d} s_{z}^{\prime}
$$

where $s_{z}^{0}$ is the arbitrarily chosen reference basal spacing of $11.5 \AA$. We carry out the simulations in a range of basal spacings and relative humidity, relevant for the one- and two-layer hydrate transition.

\section{Results and Discussion}

We compute water adsorption isotherms, the corresponding pressure normal to the clay platelets, and the free energy at several fixed values of the relative humidity for a range of basal spacings using the procedures described in our previous work. ${ }^{59}$ These results are discussed in section 3.1 for Arizona $\mathrm{Li}^{-}, \mathrm{Na}-$, and K-montmorillonite at low $(8.7 \%)$ and intermediate $(67 \%)$ relative humidity. In section 3.2, we discuss hysteresis loops of one- and two-layer hydrate transitions in a broad relative humidity range for both clay minerals and all counterions. In section 3.3, we further discuss the molecular mechanism of clay swelling hysteresis by evaluating the arrangement of counterions and water molecules.

3.1. Swelling. Figure 3 shows the simulated water content in Arizona Li-, Na-, and K-montmorillonite as a function of the basal spacing at relative humidities of 8.9 and $67 \%$. The water content increases with an increasing basal spacing and is higher in the case of a relative humidity of $67 \%$. The simulated water adsorption shows only marginal differences for the three counterions. At low relative humidity and large basal spacing, there is a small difference in water adsorption. Similar to the water adsorption isotherms that we computed in our previous work, ${ }^{60}$ we expect a decrease of the water adsorption with a further increase of the distance between the platelets. In this case, the water chemical potential will be too low to support a three-dimensional water network. Experimentally, large differences in water adsorption are usually found for clay minerals with different counterions. This is most likely caused by the fact that the basal spacing cannot be controlled in such experiments, which we do in our simulations.

In Figure 4, we show the corresponding oscillating pressure as a function of the basal spacing for Arizona $\mathrm{Li}^{-}, \mathrm{Na}-$, and $\mathrm{K}$-montmorillonite. When we increase the relative humidity, the pressure increases because more water molecules are adsorbed between the clay platelets. At spacings larger than $17.0 \AA$ and 


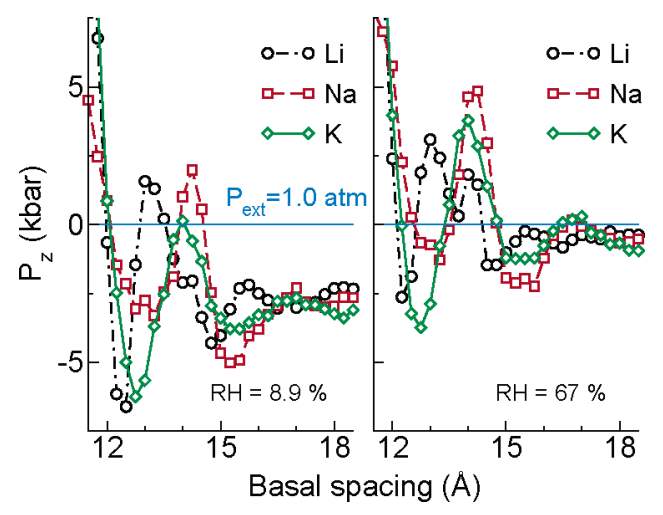

Figure 4. Simulated pressure normal to the clay platelets $\left(P_{z}\right)$ as a function of the basal spacing for Arizona $\mathrm{Li}_{-}, \mathrm{Na}-$, and $\mathrm{K}-$ montmorillonite at low (left) and intermediate (right) relative humidities of 8.9 and $67 \%$, respectively. The horizontal line indicates an external pressure of $1 \mathrm{~atm}$. The stable states correspond to the free-energy minima in Figure 5. The other data correspond to unstable states and hence the free-energy barriers.

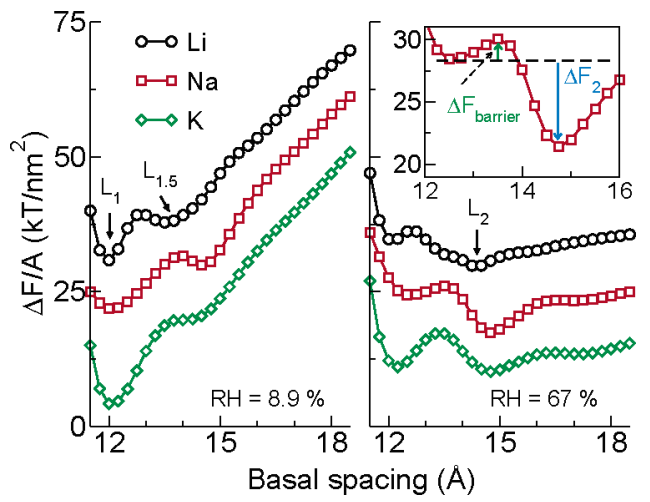

Figure 5. Simulated free energy per clay platelet area $(\Delta F / A)$, at an external pressure $\left(P_{\text {ext }}\right)$ of $1 \mathrm{~atm}$, as a function of the basal spacing for Arizona Li-, Na-, and K-montmorillonite at low (left) and intermediate (right) relative humidity of 8.9 and $67 \%$, respectively. The stable states correspond to the free-energy minima. The other data correspond to unstable states and hence the free-energy barriers. In the inset, we zoom in on a particular area of the free-energy curve of Na-montmorillonite at $67 \%$ relative humidity, in which we express the free-energy barrier $\left(\Delta F_{\text {barrier }}\right)$ and the free energy of the twolayer hydrate $\left(\Delta F_{2}\right)$ relative to the free energy of the one-layer hydrate. We shift the free-energy curves for better illustration, and therefore, only relative free-energy differences can be compared.

at an intermediate relative humidity of $67 \%$, we observe convergence of the pressure oscillations to a pressure close to the bulk pressure of $1 \mathrm{~atm}$. At low relative humidity of $8.9 \%$, the computed pressure is much lower than $1 \mathrm{~atm}$. This indicates that the clay minerals for basal spacings larger than $15.0 \AA$ are much more stable than in comparison with a relative humidity of $67 \%$. The tendency for infinite swelling is therefore much less. Especially, at spacings smaller than $15.0 \AA$, the behavior of the pressure normal to clay layers is very different for the three types of counterions. Similar trends are obtained by Whitley and Smith ${ }^{58}$ who compare Na-, Cs-, and Sr-montmorillonite with a different water model and different cation-water parameters.

Whether a clay mineral will swell for a given relative humidity can be derived directly from the free energies corresponding to the pressure curves. We show these free energies for Arizona Li-, Na-, and K-montmorillonite in Figure 5. At a low relative humidity of $8.9 \%$, the minima in the free energy indicate the occurrence of one-layer hydrates $\left(\mathrm{L}_{1}\right)$ at basal spacings of 12.0 $\AA$ for all three counterions. Furthermore, we observe that twolayer hydrates $\left(\mathrm{L}_{2}\right)$ start to develop between 14 and $15 \AA$ for the

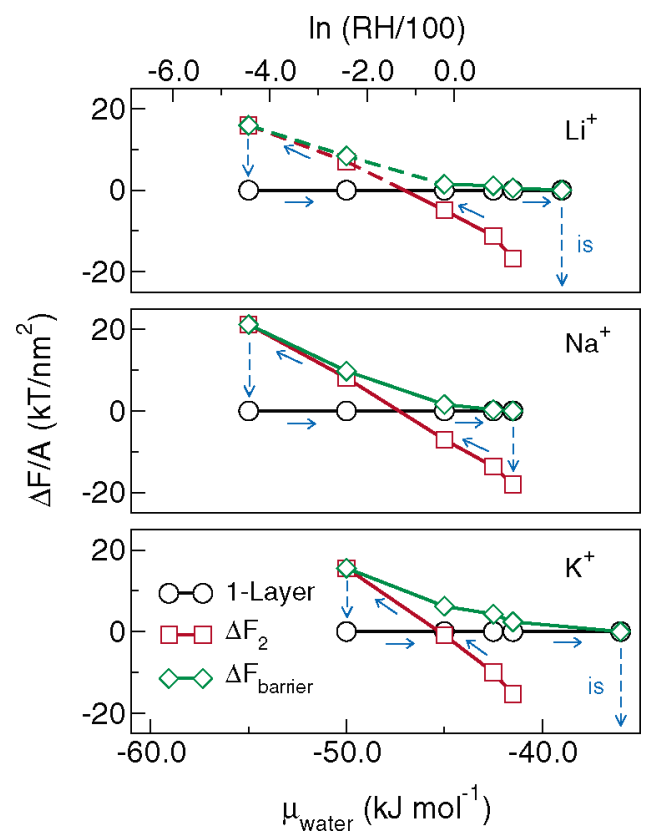

Figure 6. Simulated hysteresis loops as a function of the water chemical potential or, equivalently, the relative humidity for Arizona $\mathrm{Li}-$, Na-, and K-montmorillonite. The arrows indicate the direction of the loop. The free energy of the two-layer hydrate $\left(\Delta F_{2}\right)$ and the free energy of the barrier $\left(\Delta F_{\text {barrier }}\right)$ are expressed per clay platelet area $(A)$ and relative to the free energy of the one-layer hydrate. The dashed lines for the two-layer hydrate and the barrier of Arizona Li-montmorillonite show a qualitative indication of the $\mathrm{L}_{1.5}$ state. The dotted arrow labeled "is" denotes predictions of infinite swelling.

counterions $\mathrm{Na}^{+}$and $\mathrm{K}^{+}$. At an intermediate relative humidity of $67 \%$, the one-layer hydrate of Na-montmorillonite almost disappears and the two-layer hydrate is the most stable state at $14.75 \AA$. The free energies of the one- and two-layer hydrates (12.25 and $14.75 \AA$, respectively) of K-montmorillonite are almost equal to each other. At a low relative humidity of $8.9 \%$, we observe a minimum at $13.5 \AA$ for Li-montmorillonite, corresponding to a new state between a one- and a two-layer hydrate $\left(\mathrm{L}_{1.5}\right)$. If we increase the relative humidity to $67 \%$, the two-layer hydrate of Li-montmorillonite is the most stable state and the former $\mathrm{L}_{1.5}$ state is not stable anymore. Interestingly, basal spacings are measured that could correspond to such a state (for example, see refs 17 and 75), although the conventional explanation is that structural or chemical heterogeneities in the clay samples ${ }^{38,75}$ cause interstratification of one- and two-layer hydrates, thereby resulting in an average basal spacing. However, the experimentally measured XRD patterns are usually complex in the intermediate ranges, and therefore, it might be possible that the $\mathrm{L}_{1.5}$ state has been missed. These ideas could be an interesting subject for further experimental research.

3.2. Swelling Hysteresis. Figure 5 shows that at certain relative humidities a free-energy minimum for the one- and two-layer hydrates is encountered. One would expect that the system always goes to the lowest free-energy minimum, because this is the most stable state from a thermodynamic point of view. However, a free-energy barrier separates the one- and two-layer hydrate, and swelling or shrinking only occurs if the system is able to cross this free-energy barrier. As a result, the system can be trapped in a meta-stable state. This indicates that the free-energy barrier and meta-stable states are the origin of clay swelling

(75) Del Pennino, U.; Mazzega, E.; Valeri, S.; Alietti, A.; Brigatti, M. F.; Poppi, L. J. Colloid Interface Sci. 1981, 84, 301-309. 

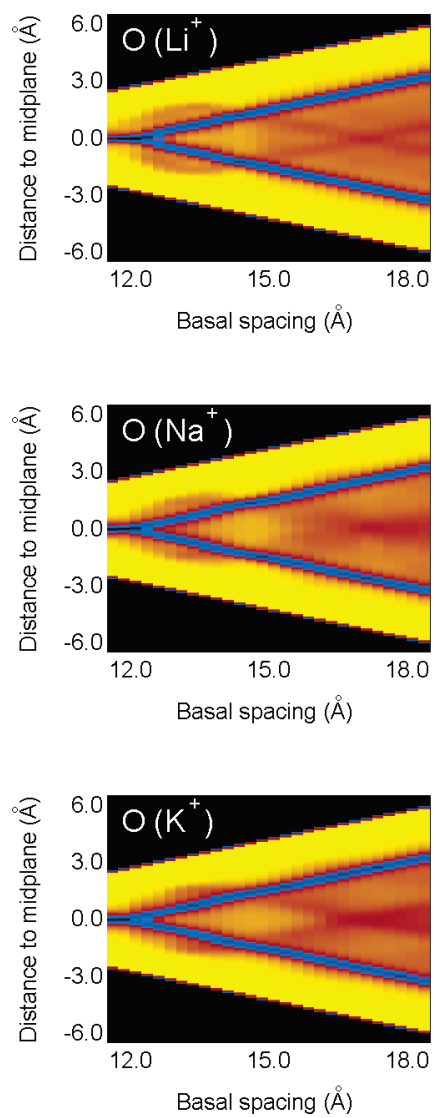
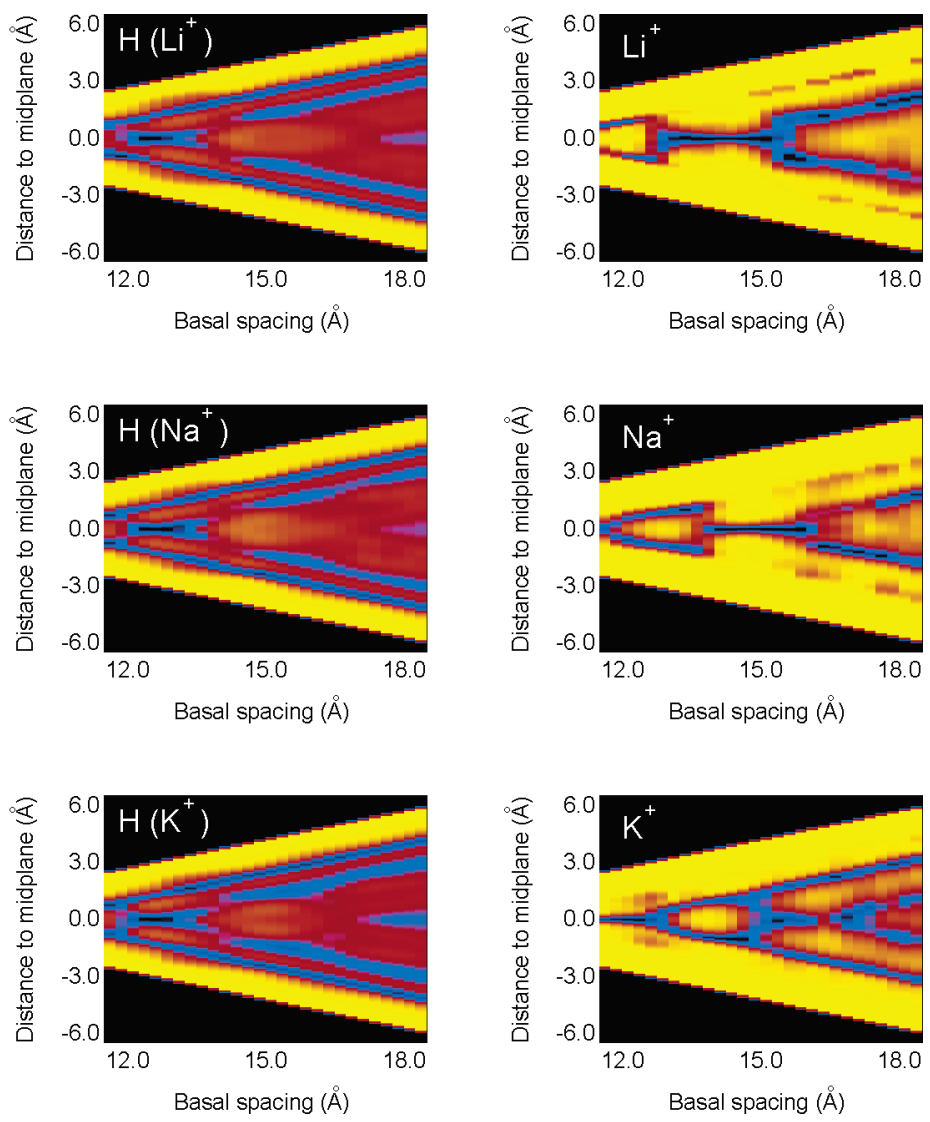

Figure 7. Simulated contour density profiles of oxygen (left), hydrogen (middle), and counterions (right) for $\mathrm{Li}^{+}$(top), $\mathrm{Na}^{+}$(middle), and $\mathrm{K}^{+}$(bottom) in the interlayer space of Arizona montmorillonite at a relative humidity of $67 \%$. The relative distance to the midplane is plotted as a function of the basal spacing. The black area represents the clay platelets. A higher intensity of the oxygen, hydrogen, or counterion positions is indicated by darker colors. We normalized each density profile on its highest peak. The stable states correspond to the free-energy minima in Figure 5. The other data correspond to unstable states and hence the free-energy barriers.

hysteresis, in agreement with earlier suggestions. ${ }^{13,20,28,38,51}$ Our molecular interpretation of this important phenomenon is different from those based on structural rearrangements $8,12,35,36$ or changes in interactions between layers upon expansion or contraction. ${ }^{10,37}$ Below, we will discuss how we quantify swelling hysteresis using the free-energy curves. In section 3.3, we will address the molecular aspects of this hysteresis in more detail.

The inset of Figure 5 displays the free energy of $\mathrm{Na}-$ montmorillonite at a relative humidity of $67 \%$, close to the region where the transition between the one- and two-layer hydrate occurs. One clearly observes two free-energy minima in this curve. The minimum at $12.50 \AA$ corresponds to the one-layer hydrate, and the minimum at $14.75 \AA$ corresponds to the twolayer hydrate, in agreement with experimentally measured basal spacings (for example, see ref 14). These two stable states are separated by a free-energy barrier, which has its maximum at $13.5 \AA$ A. Similar to this, we also observe a free-energy barrier in the case of $\mathrm{Li}$ - and $\mathrm{K}$-montmorillonite at a relative humidity of $67 \%$. These free-energy barriers are found for a certain range of relative humidities, similar to experiments where the swelling and shrinking of the one- and two-layer hydrate occurs over a specific range (for example, see ref 17). To indicate the relative humidity ranges of the free-energy barriers for all three counterions, we expressed the free energy of the barriers and two-layer hydrates relative to the free energy of the one-layer hydrate, denoted by $\Delta F_{\text {barrier }}$ and $\Delta F_{2}$, respectively. The results are collected in Figure 6, where we plotted $\Delta F_{\text {barrier }}$ and $\Delta F_{2}$ as a function of the relative humidity or, equivalently, the chemical potential for Arizona Li-, Na-, and K-montmorillonite.
The results show a loop for swelling and shrinking of clay minerals as a function of the relative humidity, which we discuss in detail for Arizona Na-montmorillonite. At a relative humidity of $8.9 \%\left(\mu_{\text {water }}=-50.0 \mathrm{~kJ} \mathrm{~mol}^{-1}\right)$, the one-layer hydrate of Na-montmorillonite has a lower free energy than the two-layer hydrate. In addition, a free-energy barrier is present between the one- and two-layer hydrate. Upon an increase of the relative humidity to $67 \%\left(\mu_{\text {water }}=-45.0 \mathrm{~kJ} \mathrm{~mol}^{-1}\right)$, more water molecules adsorb into the interlayer. This results in an increase of the pressure normal to the clay platelets (Figure 4) and a reduction of the free-energy barrier (Figure 5). At a relative humidity of $67 \%$, the free energy of the two-layer hydrate has become lower than the free energy of the one-layer hydrate. However, the expected swelling does not occur because of the free-energy barrier. Because this free-energy barrier is proportional to the usually much larger area of the clay platelets, the total free-energy barrier will be very large. We therefore have to increase the relative humidity until the free-energy barrier has (almost) disappeared. As soon as this point is reached, the one-layer hydrate can swell to the two-layer hydrate. From this situation, the reverse process of shrinking the clay mineral is not possible, because the system has to overcome a freeenergy barrier from the two- to the one-layer hydrate. To this end, the relative humidity has to be decreased until the free energies of the two-layer hydrate and the barrier are equal to each other, indicating that the free-energy barrier has disappeared. At this point, the clay mineral can shrink to the one-layer hydrate and we have completed a cycle, which we call a hysteresis loop. 

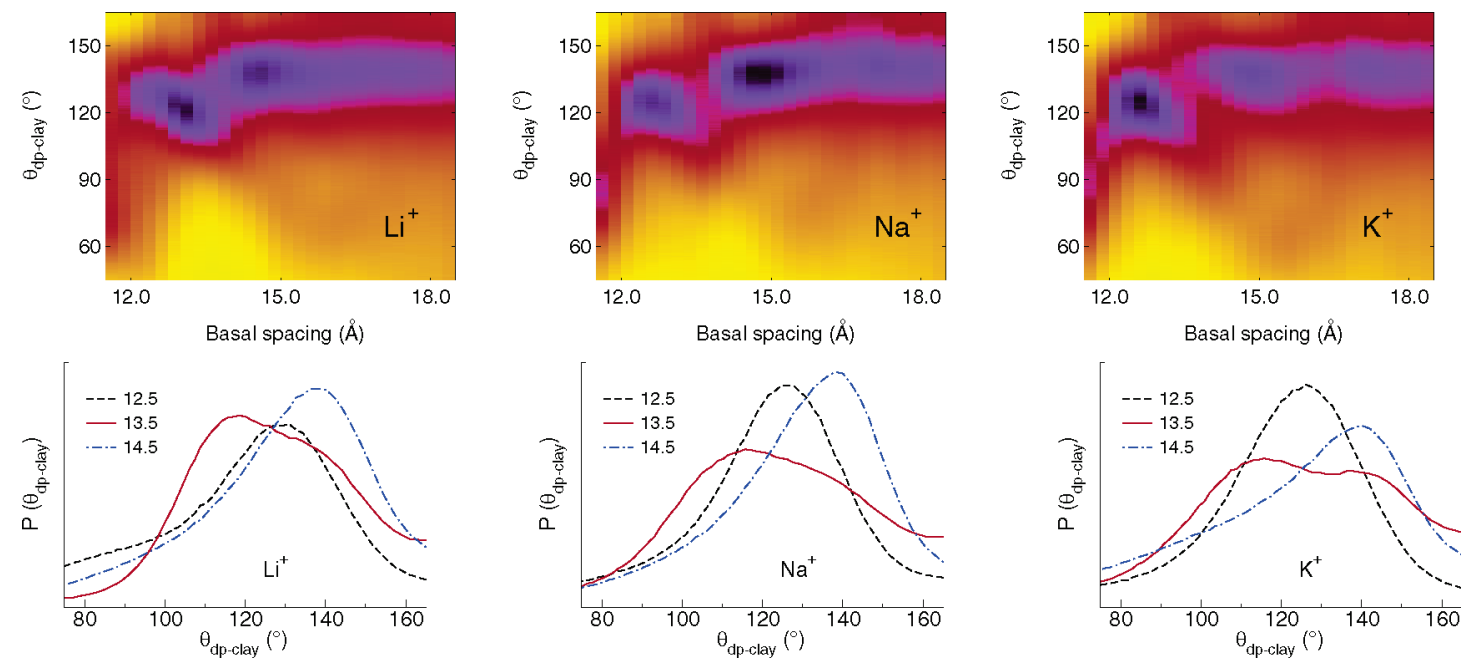

Figure 8. Simulated contour plot (top) of the angle between the water dipole and the normal vector of the clay platelets $\left(\theta_{\mathrm{dp}-\mathrm{clay}}\right)$. Shown are the angles that correspond to the water molecules in the interlayer space of Arizona Li-, Na-, and K-montmorillonite at a relative humidity of $67 \%$. The angle is plotted as a function of the basal spacing. A higher intensity of a certain angle is indicated by darker colors. The graphs shown in the second row are taken from the contour plots and show the distribution of the angle between the water dipole and the normal vector of the clay platelets for basal spacings of $12.5,13.5$, and $14.5 \AA$. The stable states correspond to the free-energy minima in Figure 5. The other data correspond to unstable states and hence the free-energy barriers.

We also observe hysteresis loops for $\mathrm{Li}^{+}$or $\mathrm{K}^{+}$cations in the interlayer of Arizona montmorillonite. The hysteresis loop for $\mathrm{Li}^{+}$is present in the same relative humidity domain as for $\mathrm{Na}^{+}$, whereas the hysteresis loop of $\mathrm{K}^{+}$is shifted to higher values of the relative humidity. For both $\mathrm{Li}^{+}$or $\mathrm{K}^{+}$, our computations predict that at a temperature of $298 \mathrm{~K}$ and an external pressure of $1 \mathrm{~atm}$ the system does not swell to a two-layer hydrate but shows infinite swelling instead. For these counterions and a water chemical potential of $-41.5 \mathrm{~kJ} \mathrm{~mol}^{-1}$, the one- and two-layer hydrates are still stable and a free-energy barrier hinders the swelling. If we increase the water chemical potential, the onelayer hydrate remains stable, but the opposite is the case for the two-layer hydrate. In Figure 6, we qualitatively show the range in water chemical potential of the $\mathrm{L}_{1.5}$ state for Arizona Limontmorillonite. For a water chemical potential lower than -45.0 $\mathrm{kJ} \mathrm{mol}^{-1}$, the free-energy barrier is the barrier to jump from a one-layer hydrate to the $\mathrm{L}_{1.5}$ state, instead of the two-layer hydrate. For a water chemical potential between -45.0 and $-50.0 \mathrm{~kJ}$ $\mathrm{mol}^{-1}$, the two-layer hydrate shrinks into the $\mathrm{L}_{1.5}$ state. In practice, our simulations predict that the $\mathrm{L}_{1.5}$ state only occurs during desorption and shrinking.

Experimentally, the counterion $\mathrm{K}^{+}$is known for its swelling inhibition properties, ${ }^{42}$ and one-layer hydrates are commonly observed for K-montmorillonite. ${ }^{26}$ Our results for $\mathrm{K}^{+}$agree with these observations, as we predict that the one-layer hydrate of $\mathrm{K}^{+}$is stable up to relatively high values of the water chemical potential (Figure 6). A two-layer hydrate is commonly observed for $\mathrm{Li}^{+}$. In comparison to our previous work, ${ }^{60}$ we know that the one- to two-layer hydrate transitions are sensitive for cationclay interactions. We therefore believe that the model can be improved using hysteresis loops and a fine-tuned effective cation$\mathrm{O}_{\text {clay }}$ potential, which has been successful in comparable systems. ${ }^{76}$ The swelling and shrinking of the one- and two-layer hydrate for several types of clay minerals ${ }^{26}$ and counterions ${ }^{15}$ usually occur between approximately 50 and $100 \%$ relative humidity, corresponding to water chemical potentials of -45.7 and $-44.5 \mathrm{~kJ} \mathrm{~mol}^{-1}$, respectively. The simulated hysteresis loops extend over this experimental domain (Figure 6) but are wider

(76) Calero, S.; Dubbeldam, D.; Krishna, R.; Smit, B.; Vlugt, T. J. H.; Denayer, J. F. M.; Martens, J. A.; Maesen, T. L. M. J. Am. Chem. Soc. 2004, 126, $11377-$ 11386.
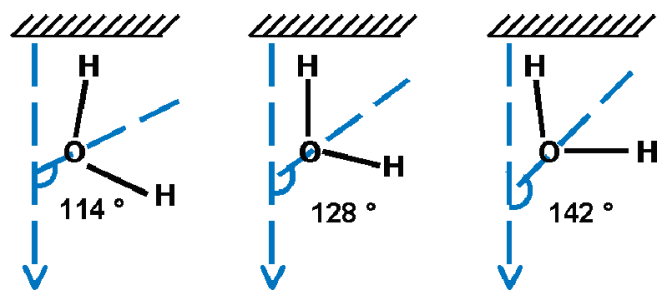

Figure 9. Illustrations of preferred orientations of water molecules in the interlayer of clay minerals. Shown are the cases for which the dipole of the water molecule has an angle of $114^{\circ}, 128^{\circ}$, and $142^{\circ}$ with the clay normal.

than experimentally observed. In the experiments, local changes in the clay structure, impurities in the interlayer, or effects at the edges of the crystal may cause nucleation and lower the freeenergy barrier significantly, resulting in a smaller hysteresis loop than observed in simulations with a perfect and rigid clay structure.

3.3. Molecular Interlayer Structure. Although the type of counterion only has a small influence on the simulated water content at a given relative humidity, we find a significant effect on the simulated pressure, free energy, and hysteresis loops (section 3.2). Experimentally, it is found that there is an increasing tendency for swelling with a decreasing cation size and increasing hydration energy. ${ }^{10,15,28}$ In our previous work, we observed a trend in swelling behavior for $\mathrm{Li}^{+}, \mathrm{Na}^{+}$, and $\mathrm{K}^{+}$and the MCY water model ${ }^{59}$ ). Computations by Whitley and $\mathrm{Smith}^{58}$ also show the dependence of the swelling behavior on the type of cation. This motivated us to study the interlayer structure in more detail. First, we discuss the orientation of the water molecules, followed by the counterion arrangement. On the basis of these insights, we then propose models of the interlayer structure and give a molecular mechanism of swelling hysteresis.

3.3.1. Orientation of Water Molecules. In Figure 7, we plot contour density profiles of the oxygen and hydrogen atoms of water, similar to ref 56, at a relative humidity of $67 \%$ in Arizona montmorillonite. The contour density profiles are constructed from density profiles at each basal spacing, and we normalized each density profile by its highest peak. Hence, the figures show the relative distance of the oxygen and hydrogen atoms from the midplane as a function of the basal spacing. Clearly, the simulated density of these atoms in the interlayer space hardly depends 

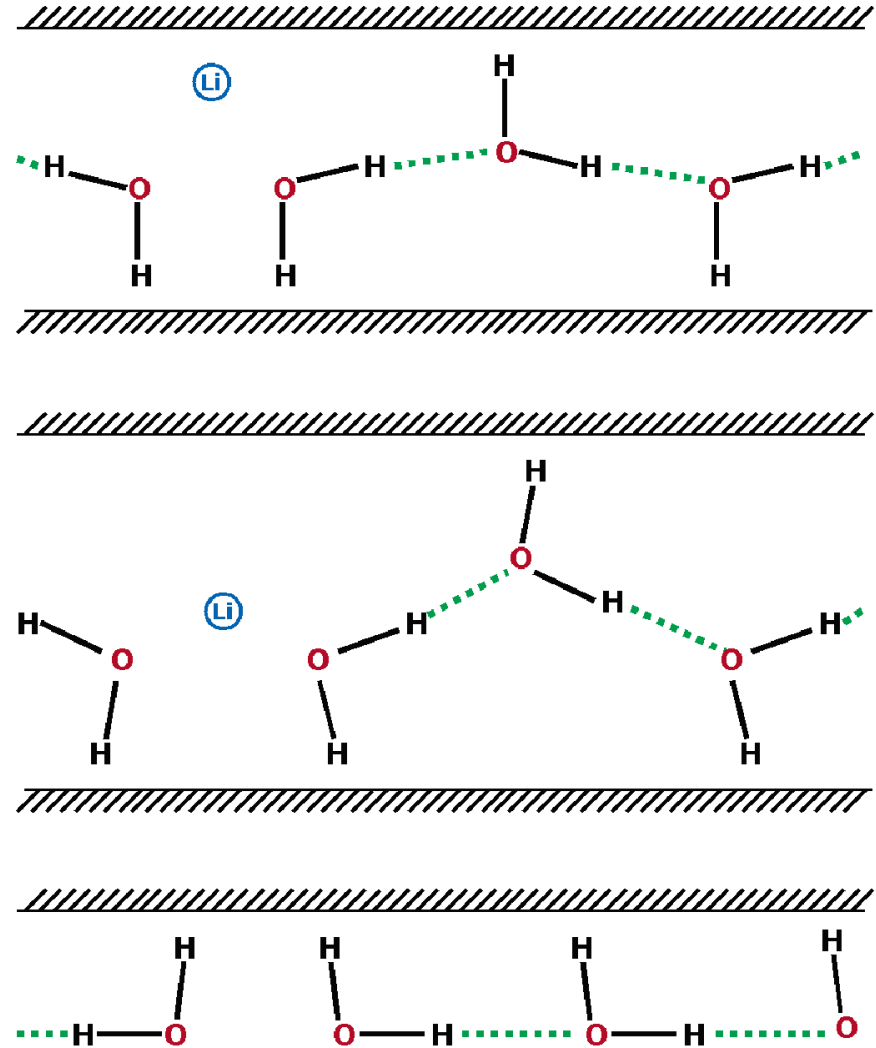

(11)

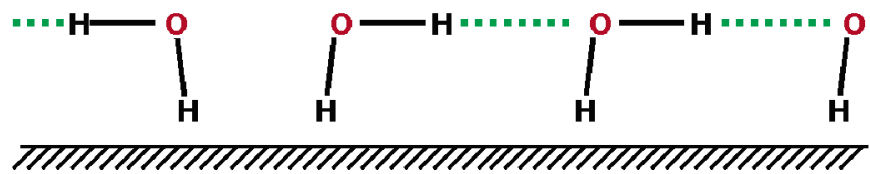

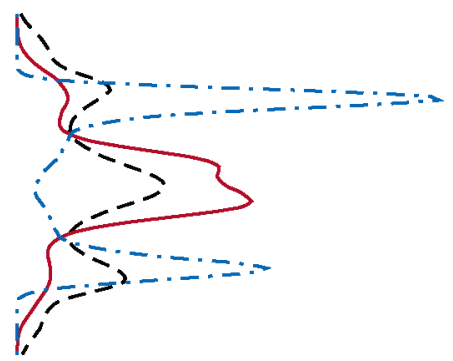
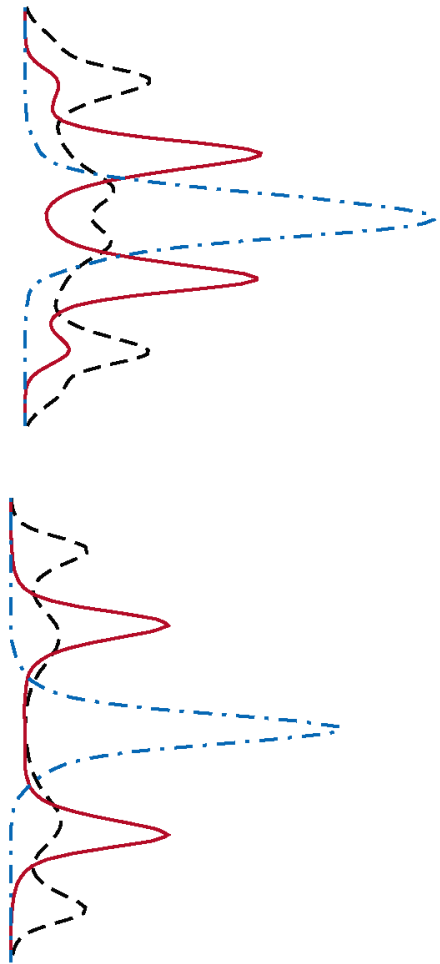

Figure 10. Illustrations and density profiles of the water orientation and arrangement of $\mathrm{Li}^{+}$in the interlayer during swelling from a oneto a two-layer hydrate. The figures show idealized configurations at 12.5 (top), 13.5 (middle), and $14.5 \AA$ (bottom), on the basis of Figures 7 and 8. The dotted lines in the picture indicate hydrogen bonds. In the density profiles, the solid, dashed, and dashed-dotted lines represent oxygen, hydrogen, and $\mathrm{Li}^{+}$atoms, respectively.

upon the type of counterion. The oxygen atoms form one layer at small basal spacings, corresponding to the one-layer hydrate. With increasing basal spacing, the oxygen atoms form two and eventually three layers. We observe similar trends for the hydrogen atoms, which are organized in three layers at small basal spacings. At a basal spacing of $13.25 \AA$, the middle peak splits up in two. At basal spacings of approximately $17.0-18.5 \AA$, these two middle peaks develop into three peaks and three layers of water molecules are formed.

To obtain a clearer picture of the water orientation in the interlayer, we show contour plots of the angle between the water dipole and the normal vector of the clay platelets in Arizona $\mathrm{Li}$-, $\mathrm{Na}$-, and K-montmorillonite at a relative humidity of $67 \%$ (Figure 8). In other words, Figure 8 shows the simulated reorientation of the water molecules with varying basal spacing. Figure 8 also shows the distributions of the angles for basal spacings of 12.5 , 13.5, and $14.5 \AA$, and these graphs are taken from the contour plots. Similar to the contour density profiles (Figure 7), the water orientation also shows little dependence on the type of counterion. For one-layer hydrates with a basal spacing of $12.5 \AA$, we see a preferred angle of the water dipole with the normal vector of the closest clay platelet of approximately $125^{\circ}$. The snapshots and density profiles show that this orientation is realized with one of the hydrogen atoms pointing to the clay surface. The preferred angle decreases when the basal spacing is increased to $13.5 \AA$, followed by a jump in the preferred angle to approximately $140^{\circ}$ with a further increase of the basal spacing. This jump corresponds to the transition of a one- to a two-layer hydrate. The remarkable aspect is that, independent of the type of counterion, an almost qualitatively similar pattern for the water molecules is observed. It should be noted that large differences are usually found for clay minerals with different counterions. This is most likely caused by the fact that the basal spacing cannot be controlled in such experiments, which we do in our simulations.

3.3.2. Arrangement of the Counterions. In Figure 7, we also show simulated contour density profiles of the counterions at a relative humidity of $67 \%$. Our results are in agreement with density profiles by Boek et al. ${ }^{42}$ Because our simulated clay model does not contain tetrahedral substitutions, we do not observe counterions that remain adsorbed to such sites at the clay surface. The arrangement of counterions depends upon the type of cation. At a small basal spacing of approximately $12.5 \AA$, the counterions form outer-sphere complexes, which refers to a relatively loose adsorption to the octahedral charged sites. ${ }^{42}$ Because the $\mathrm{Na}^{+}$ counterions are larger, their position is further away from the clay surface. Because of the even larger size of $\mathrm{K}^{+}$, these counterions form one layer in the midplane. When the basal 

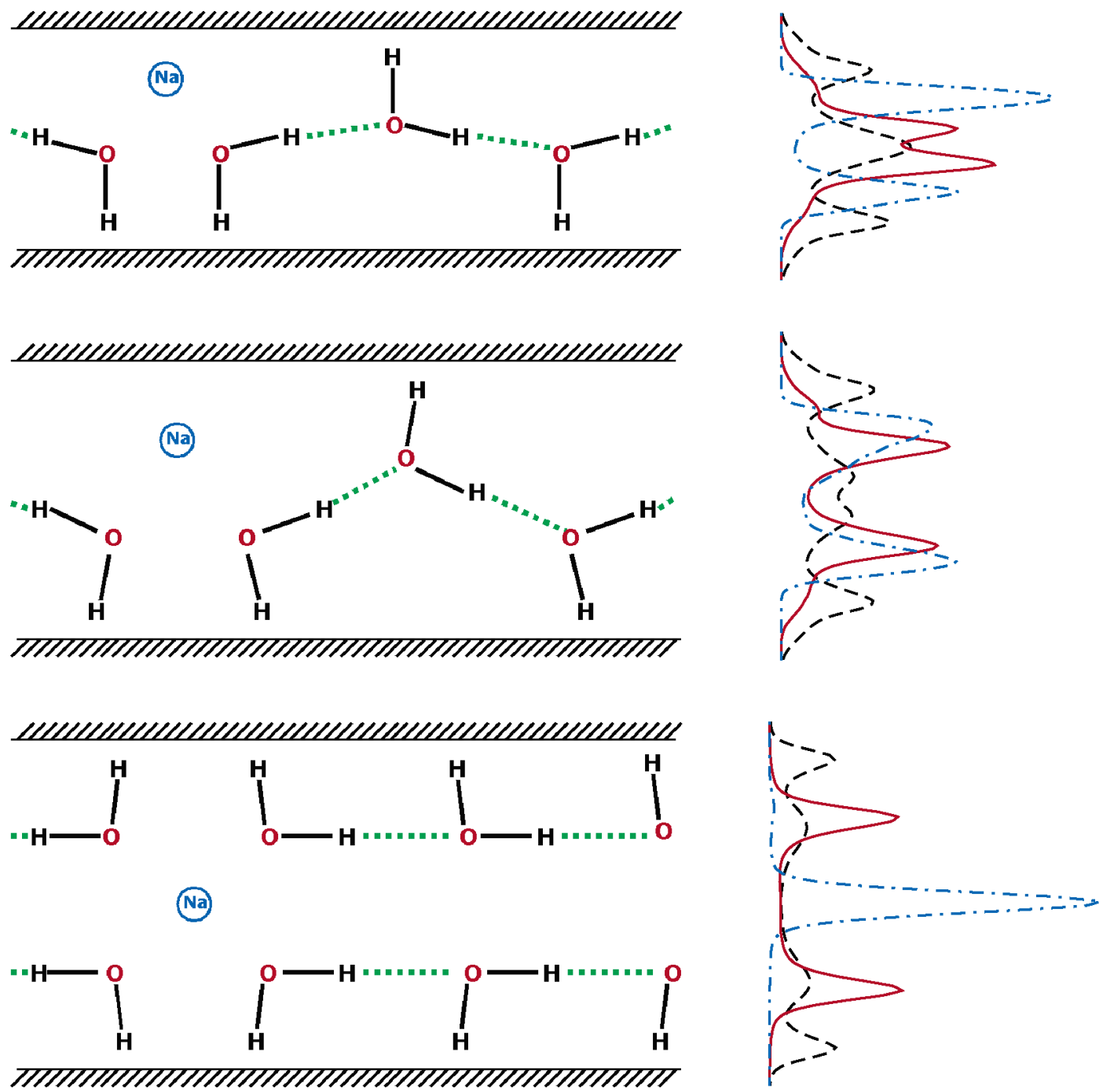

Figure 11. Illustrations and density profiles of the water orientation and arrangement of $\mathrm{Na}^{+}$in the interlayer during swelling from a oneto a two-layer hydrate. The figures show idealized configurations at 12.5 (top), 13.5 (middle), and $14.5 \AA$ (bottom), on the basis of Figures 7 and 8 . The dotted lines in the picture indicate hydrogen bonds. In the density profiles, the solid, dashed, and dashed-dotted lines represent oxygen, hydrogen, and $\mathrm{Na}^{+}$atoms, respectively.

spacing is increased to $13.5 \AA$, the $\mathrm{Li}^{+}$counterions become hydrated in the midplane and form one layer, whereas the $\mathrm{Na}^{+}$ counterions remain adsorbed to the surface. We also observe that the $\mathrm{K}^{+}$counterions form two adsorbed layers at the clay surface. At a basal spacing of $14.5 \AA$, the $\mathrm{Li}^{+}$and $\mathrm{Na}^{+}$counterions are both present in one layer, whereas the $\mathrm{K}^{+}$counterions are still adsorbed to the clay surface. When the basal spacing is further increased to $18.5 \AA$, almost all counterions become hydrated in two layers. We already mentioned in section 3.3.1 that three layers of water molecules are formed for a basal spacing of $18.5 \AA$. The molecular structure is therefore such that each layer of counterions is embedded between two layers of water molecules. In agreement with the trend described above, smaller counterions start forming these two layers for smaller values of the basal spacing. An important difference is that a relatively large fraction of the $\mathrm{K}^{+}$counterions remains adsorbed to the clay platelets, even at a large basal spacing. For $\mathrm{Li}^{+}$and $\mathrm{Na}^{+}$, we observe traces of such adsorption to the clay platelets. Because of the relatively large size of $\mathrm{K}^{+}$and relatively small hydration energy, solvation by water molecules in a two-layer hydrate is less favorable. ${ }^{77}$ Our results therefore support the suggestion of

(77) Sposito, G.; Skipper, N. T.; Sutton, R.; Park, S.-H.; Soper, A. K.; Greathouse, J. A. Proc. Natl. Acad. Sci. U.S.A. 1999, 96, 3358-3364.
Boek et al. ${ }^{42}$ that $\mathrm{K}^{+}$counterions are able to screen the negatively charged clay surface more effectively than $\mathrm{Li}^{+}$and $\mathrm{Na}^{+}$. Therefore, there is no driving force to form a two-layer hydrate of K-montmorillonite, in contrast with $\mathrm{Li}$ - and Na-montmorillonite. The lack of this driving force may be an explanation why a relatively high free-energy barrier remains present at a high relative humidity (section 3.2 ) and why $\mathrm{K}^{+}$can inhibit clay swelling. ${ }^{26,42}$

We also observed differences for the counterion arrangement in the interlayer space of Arizona montmorillonite and the MCY water model ${ }^{59}$ Density profiles of two-layer hydrates show that $\mathrm{Li}^{+}$forms one layer in the midplane; the $\mathrm{Na}^{+}$counterions show a distribution of solvation in the midplane and clay surface adsorption; and $\mathrm{K}^{+}$predominantly adsorbs to the clay surface. For two-layer hydrates computed with the SPC/E water model and $\mathrm{Na}^{+}$and $\mathrm{Cs}^{+}$counterions, it was found that $\mathrm{Na}^{+}$forms a layer in the midplane, whereas $\mathrm{Cs}^{+}$shows clay surface adsorption. ${ }^{58}$ Apparently, $\mathrm{K}^{+}$and $\mathrm{Cs}^{+}$both have more affinity for clay surface adsorption in comparison with $\mathrm{Li}^{+}$and $\mathrm{Na}^{+}$.

3.3.3. Models of Interlayer Structures. In a clay mineral system, there is a balance between surface complexation of the counterions and hydration by water, which significantly depends upon the type of cation, basal spacing, and type of clay mineral. If we 

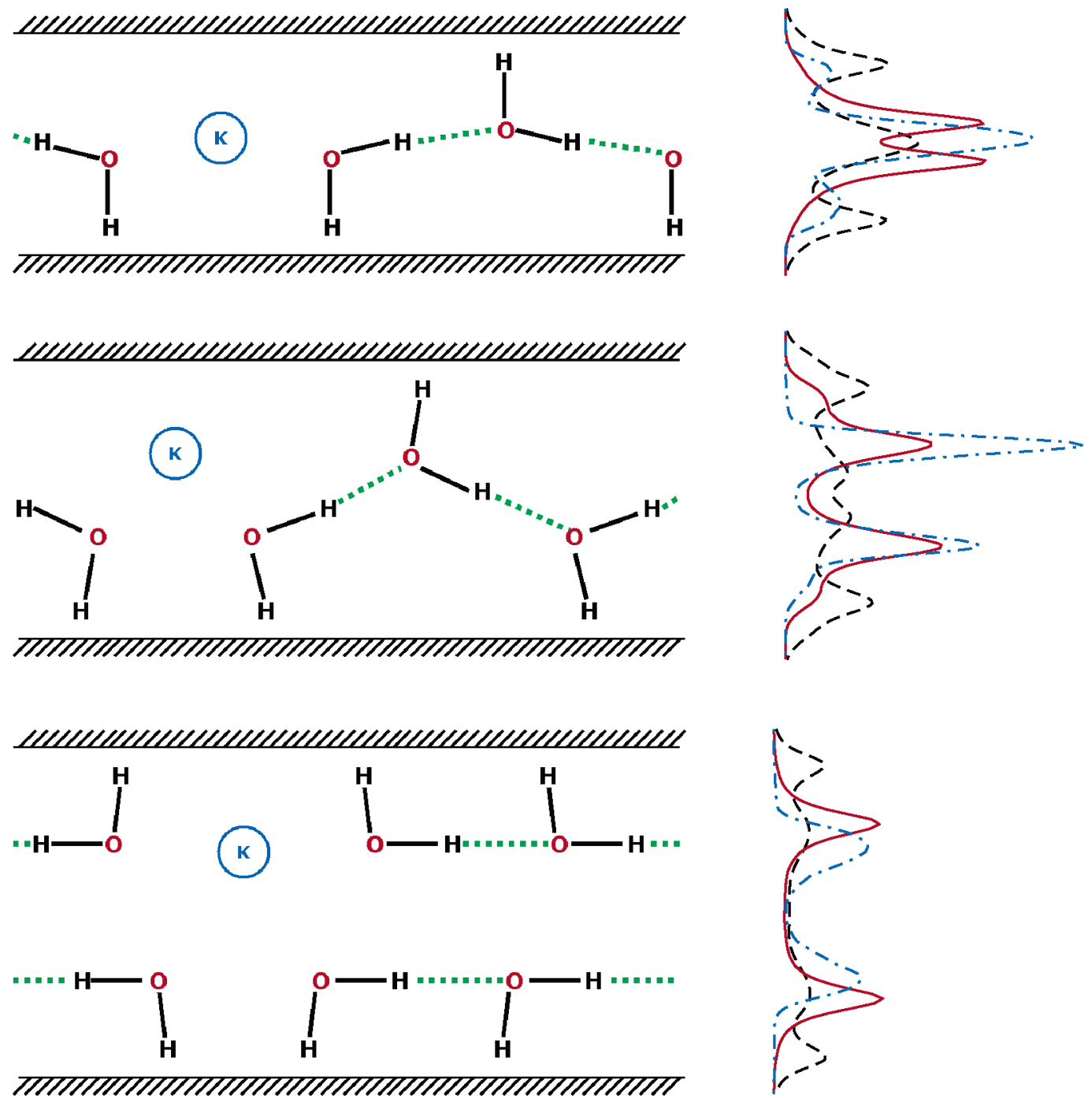

Figure 12. Illustrations and density profiles of the water orientation and arrangement of $\mathrm{K}^{+}$in the interlayer during swelling from a oneto a two-layer hydrate. The figures show idealized configurations at 12.5 (top), 13.5 (middle), and $14.5 \AA$ (bottom), on the basis of Figures 7 and 8 . The dotted lines in the picture indicate hydrogen bonds. In the density profiles, the solid, dashed, and dashed-dotted lines represent oxygen, hydrogen, and $\mathrm{K}^{+}$atoms, respectively.

compare the pressure normal to the clay platelets at basal spacings of $12.5,13.5$, and $14.5 \AA$ (Figure 4), we observe that the pressure is significantly different for the three counterions. Because the arrangement of the counterions depends upon the size and hence the hydration energy, we think that this arrangement induces differences in pressure. In a recent review, ${ }^{78}$ it was suggested that the water structure in the interlayer of swelling clay minerals is mainly controlled by the type of counterion and hence the hydration energy. On the other hand, others claim that water molecules are part of a structure that is probably determined by the silicate itself. ${ }^{75}$ Furthermore, they conclude that one of the bonds of the water molecules in the interlayer space is almost orthogonal to the surface. Suquet et al. ${ }^{79}$ and Prost ${ }^{80}$ proposed structures in which the water molecules have one bond parallel to the surface or one bond orthogonal to the surface, respectively.

Our simulations with three different counterions show a similar arrangement of the water molecules. In a simulation of a neutral pyrophyllite, i.e., without any counterions in the interlayer space, we compute that the preferred angle of the water dipole and the

(78) Michot, L. J.; Villiéras, F.; François, M.; Bihannic, I.; Pelletier, M.; Cases, J.-M. C. R. Geoscience 2002, 334, 611-631.

(79) Suquet, H.; de la Calle, C.; Pezerat, H. Clays Clay Miner. 1975, 23, 1-9. (80) Prost, R. Proc. Int. Clay Conf. 1975, 351-359. clay normal is approximately $65^{\circ}$. The density profiles and snapshots reveal that water molecules point their oxygen atoms to the clay surface. The presence of monovalent counterions causes a change in orientation of the water molecules, pointing a hydrogen atom to the clay surface and the $\mathrm{OH}$ bond almost orthogonal to the clay surface. As a consequence, the preferred angle between the water dipole and the clay normal is approximately $115-140^{\circ}$, depending upon the basal spacing. Interestingly, this structure is observed for all counterions. We also observe that the swelling behavior of the different counterions is different. This suggests that the differences in the pressure curves (Figure 4) and hence the free-energy barriers (Figures 5 and 6) are caused by the different arrangements of the counterions. We summarize our conclusions schematically in Figures 9-12. The left picture in Figure 9 shows an orientation of a water molecule with an angle of $114^{\circ}$, close to the preferred angle that we computed for a basal spacing of $13.5 \AA$. The angle of the water dipole and the clay normal in the middle and right pictures correspond to the preferred angles of $128^{\circ}$ and $142^{\circ}$, respectively, which are close to the preferred angles for the one- and two-layer hydrates (Figure 8). With these three orientations and taking into account the shifts in oxygen and hydrogen density as a function of the basal spacing (Figure 7), we create models of ideal interlayer structures at basal spacings of $12.5,13.5$, and $14.5 \AA$. 


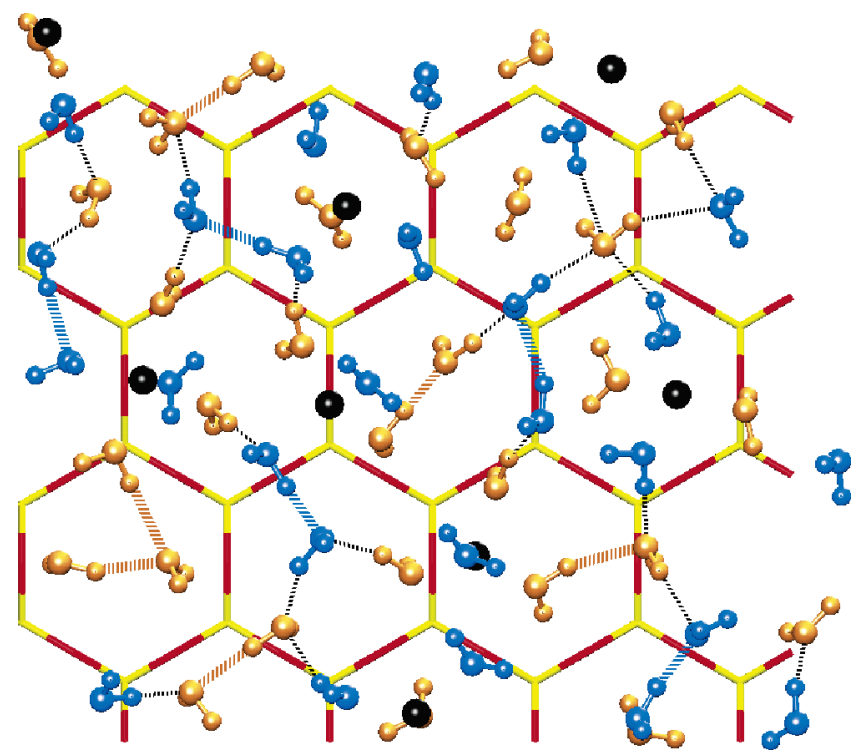

Figure 13. Projection of the $x y$ plane of Arizona Li-montmorillonite with a basal spacing of $13.5 \mathrm{~A}$ and at a relative humidity of $67 \%$. Water molecules and in-plane hydrogen bonds are colored orange (light gray) and blue (dark gray) for the bottom and top layers, respectively. Hydrogen bonds between water molecules of the bottom and top layers are black and indicated with thinner lines than the in-plane hydrogen bonds. The $\mathrm{Li}^{+}$counterions are black.

At $12.5 \AA$, the water molecules preferentially have one $\mathrm{O}-\mathrm{H}$ bond perpendicular to the clay surface and form hydrogen bonds with the closest clay surface and with water molecules on the opposite side. The $\mathrm{Li}^{+}$and $\mathrm{Na}^{+}$counterions are bounded to the upper and lower clay surface, whereas the larger $\mathrm{K}^{+}$counterions are located in the midplane. When the basal spacing is increased to $13.5 \AA$, the water molecules reorient in such a way that the angle between their dipole and the clay normal becomes smaller, with a value of approximately $114^{\circ}$. As we can derive from Figures 10-12, the hydrogen bonds between the molecules of the top and bottom layer are preserved. In this situation, the $\mathrm{Na}^{+}$ and $\mathrm{K}^{+}$counterions are adsorbed to the clay surfaces, whereas the smaller $\mathrm{Li}^{+}$counterions have already moved to the midplane. Interestingly, this structure corresponds to the $\mathrm{L}_{1.5}$ state that we have identified in the previous sections, and thus, we have found a molecular explanation for this state. With a further increase of the basal spacing to $14.5 \AA$, the hydrogen bonds between the layers are broken and the water molecules reorient in such a way that one of the $\mathrm{O}-\mathrm{H}$ bonds is parallel to the clay surface, resulting in an angle of approximately $142^{\circ}$ between the water dipole and the normal vector of the clay surface. For this structure, new hydrogen bonds are formed in each of the two layers. The $\mathrm{Li}^{+}$ and $\mathrm{Na}^{+}$counterions move to the interlayer midplane where they are coordinated by water molecules from each layer. For $\mathrm{Na}^{+}$, this structure agrees with a proposed structure of a two-layer hydrate in saponite. ${ }^{79}$ The $\mathrm{K}^{+}$counterions are adsorbed to the clay surface and are also coordinated by water molecules from each layer. In comparison, with a basal spacing of $13.5 \AA$, the $\mathrm{K}^{+}$counterions are slightly closer to the midplane. As can be seen from Figure 7 at $14.5 \AA$, the tendency for the interlayer midplane is increasing.

Figures 10-12 schematically show two-dimensional models of the interlayer structure of one-, one- and a half, and two-layer hydrates, but the three-dimensional situation is more complex. We illustrate this in Figure 13, by showing a projection of the interlayer structure of Arizona Li-montmorillonite on the $x y$ surface of the clay mineral, in the case of a basal spacing of 13.5 $\AA$. The figure shows that $\mathrm{Li}^{+}$counterions are coordinated by four water molecules, which form strings with other water molecules. Although the observed preferential sequence of hydrogen bonds between molecules of separate layers are in agreement with our model (Figures 10-12), hydrogen bonds between molecules of one layer are also present in the strings. Most of the water molecules have one $\mathrm{O}-\mathrm{H}$ bond almost orthogonal to the clay surface, which also agrees with our model.

3.3.4. Molecular Mechanism of Swelling Hysteresis. With our models of the interlayer structure given above, we can explain our observations for the pressure, free energy, and swelling hysteresis. Our interpretation is that the reorientation of the water molecules induces the breaking of hydrogen bonds between water layers on each side of the clay surface, and new hydrogen bonds within each water layer are predominantly formed. The breaking and formation of these bonds dominate the oscillations in the pressure normal to the clay layers (Figure 4), resulting in freeenergy barriers (Figure 5) and hysteresis (Figure 6). The counterions influence the pressure oscillations, which are related to their different position in the interlayer and their coordination with water molecules. In the case of a one-layer hydrate, an increase of the relative humidity leads to an increase of water adsorption and therefore a small increase in basal spacing and a small rearrangement of the counterions and water molecules. This continues until a critical relative humidity is reached, depending upon the type of counterion. In the case of Arizona Na-montmorillonite and at critical relative humidity, the system swells and the counterions leave the clay surface. The final state is a two-layer hydrate. For Arizona Li-montmorillonite such a mechanism also occurs. Theoretically, the mechanism is the same for potassium. However, these counterions prefer adsorption to the clay surface, and thereby, they screen the charge of the surface. As a consequence, a very high water chemical potential is needed to accomplish swelling (Figure 6).

With the two-layer hydrate as a starting point, a decrease in the relative humidity induces desorption of water molecules from the interlayer space, followed by a relatively small decrease of basal spacing and small rearrangement of the counterions and water molecules. However, the reverse pathway requires that hydrogen bonds between the molecules in each water layer need to be broken and new bonds need to be formed between the two layers of water molecules. This can only be accomplished by desorption of water molecules from the system, and therefore, hysteresis occurs. Once a critical relative humidity is reached, the system can shrink to the one-layer hydrate in the case of $\mathrm{Na}^{+}$ and $\mathrm{K}^{+}$. A different situation is the case for Arizona Limontmorillonite. For this system, in a small range of the relative humidity, our predictions point to a mechanism in which an extra step is taken during the transition from a two- to a onelayer hydrate. Related to their size and hydration, $\mathrm{Li}^{+}$counterions can move to the midplane of the clay mineral at a basal spacing of approximately $13.5 \AA$, thereby forming a one- and a half state. Interestingly, experimental intermediate basal spacings of 13.8 and $13.5 \AA$ have been reported for $\mathrm{Li}^{+}$and $\mathrm{Mg}^{2+}$, respectively. ${ }^{75}$ However, in the discussion of this work, it was pointed out that stable complexes having intermediate values of the basal spacing are thought not to occur. When X-ray diffraction measurements show intermediate values of the basal spacing, they must be attributed to interstratification of two or more swelling phases. ${ }^{75}$ Our simulations, however, suggest that intermediate values of the basal spacing or an $\mathrm{L}_{1.5}$ state are physically meta-stable. It would be interesting if molecular simulations can also reproduce intermediate basal spacings for $\mathrm{Mg}^{2+}$ and if future experimental research can verify the occurrence of such intermediate states. 


\section{Conclusions}

We study the swelling of Arizona Li-, Na-, and K-montmorillonite at small-layer spacings by computing the water content, the pressure normal to the clay mineral layers, and the free energy. We show that the stability of layered hydrates depends upon the type of counterion and the relative humidity, at a temperature of $298 \mathrm{~K}$ and an external pressure of $1.0 \mathrm{~atm}$. The swelling and shrinking of one- and two-layer hydrates show hysteresis, in agreement with experimental results. This hysteresis is explained by a free-energy barrier that separates the stable layered hydrates. Our simulations show that the swelling and shrinking of clay minerals is dominated by the formation and breaking of hydrogen bonds within and between different water layers. Independent of the type of counterion, we observe a similar water network. Interestingly, the location of the counterions depends upon their size. The relatively large $\mathrm{K}^{+}$counterions will only desorb from the clay platelets as soon as sufficient space in the water network exists. Therefore, these counterions increase the free-energy barrier and may act as a swelling inhibitor. On the other hand, the smaller $\mathrm{Li}^{+}$counterions can be accommodated more easily in the water network. This results in catalyzing the swelling and shrinking process, by forming a new state with a basal spacing between those of a one- and a two-layer hydrate. This new state is an alternative explanation for the simultaneous occurrence of two or more swelling phases.

Acknowledgment. This work is supported by The Netherlands Research Council for Chemical Sciences (NWO-CW) through PIONIER and by FOM (Stichting Fundamenteel Onderzoek der Materie). We thank Prof. D. L. Bish and Dr. E. S. Boek for helpful discussions.

LA051367Q 